\title{
Investigation of the Shallow Hydrogeologic System on St. Catherines Island Georgia
}

R. Kelly Vance ${ }^{1}$, James S. Reichard ${ }^{1}$, Jacque L. Kelly ${ }^{1}$,

Brian K. Meyer ${ }^{2}$, Fredrick J. Rich ${ }^{1}$, Gerald R. Diederich ${ }^{1 *}$, Anne M. Delua ${ }^{1^{*}}$
(1) Georgia Southern University
$\left(1^{*}\right)$ Georgia Southern Undergraduates
(2) Georgia State University

Geological Society of America: Southeastern Section $66^{\text {th }}$ Annual Meeting

A Project supported by Georgia Sea Grant, St. Catherines Island Foundation Research Program and Dept. of Geology \& Geography, GSU 


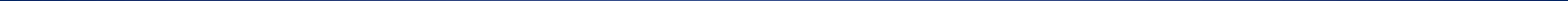




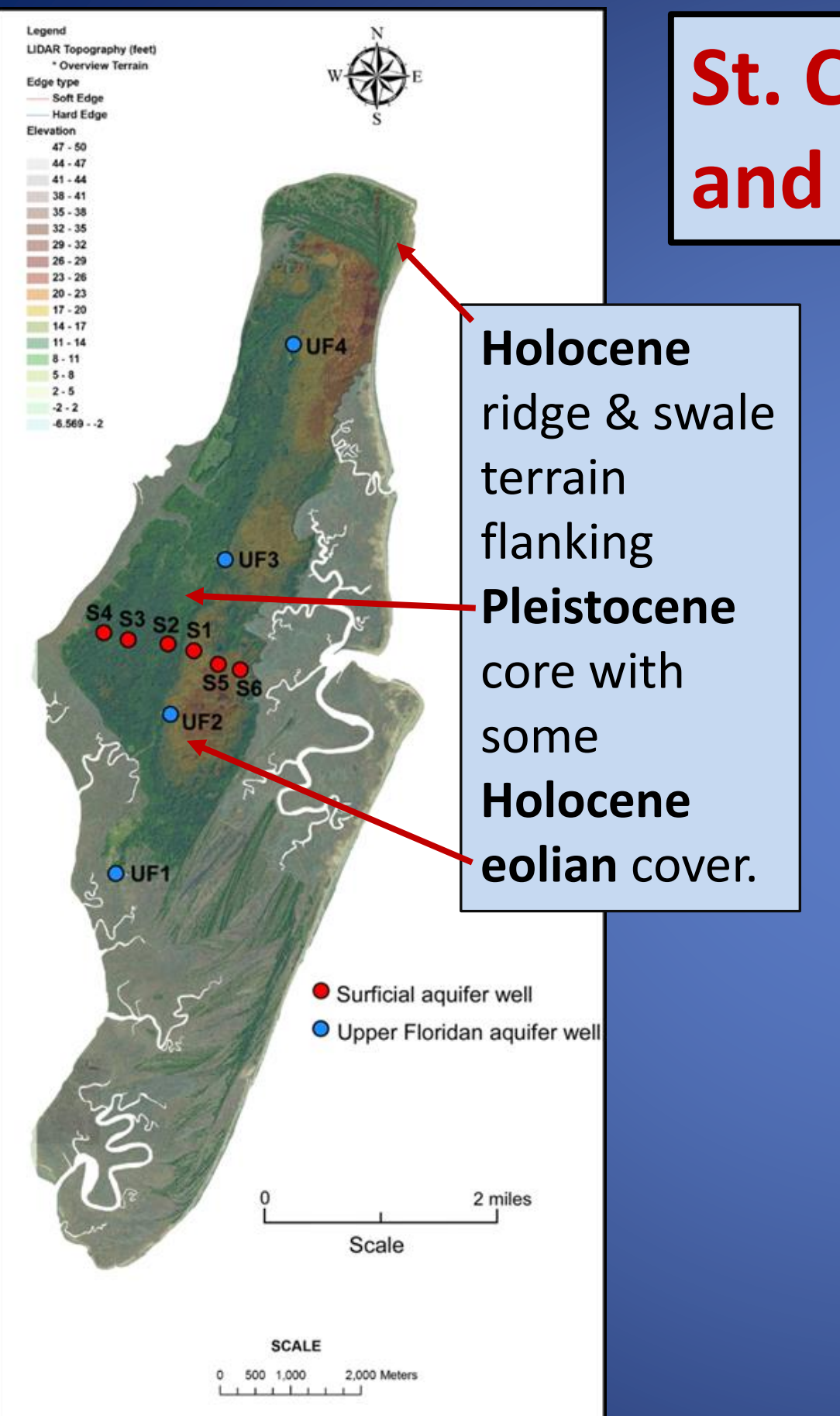

Sampling and analyses of wells in Upper Floridan indicate saline water contamination from below (Reichard et al., 2014).

Salt water intrusion by upconing and the past occurrence of Artesian springs requires structural access through confining layers.

Chloride spikes (salt water intrusion) detected in the surficial aquifer. 
St. Catherines Island shallow well sites - in sand $<7.3 \mathrm{~m}$ depth
$\mathrm{SCl}$ wetlands overlay (pre-1960)

\section{Current Research:}

* Determine salt water intrusion pathways into surficial aquifer.

*Evaluate potential for communication with the Upper Floridan aquifer.

\section{Methods:}

- Monitoring head and water chemistry

- resistivity \& GPR surveys

- coring as needed. 


\section{Potential salt water intrusion pathways:}

- Flooding and vertical infiltration

- Lateral intrusion via tabular sand aquifers or buried channel sands

- Lateral intrusion through structural pathways (joints, faults)

- Vertical intrusion through structural pathways (joints, faults, sag structures) 
Faults and joints focused dissolution in Upper Floridan carbonates. Collapse of deep caverns produced sag structures and basins in surficial sediments.

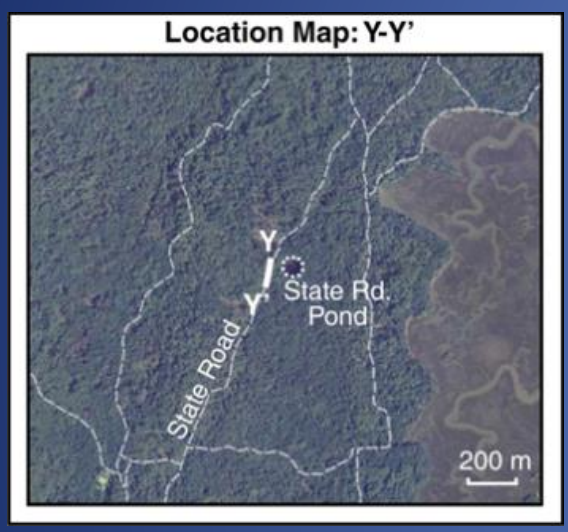

1 meter

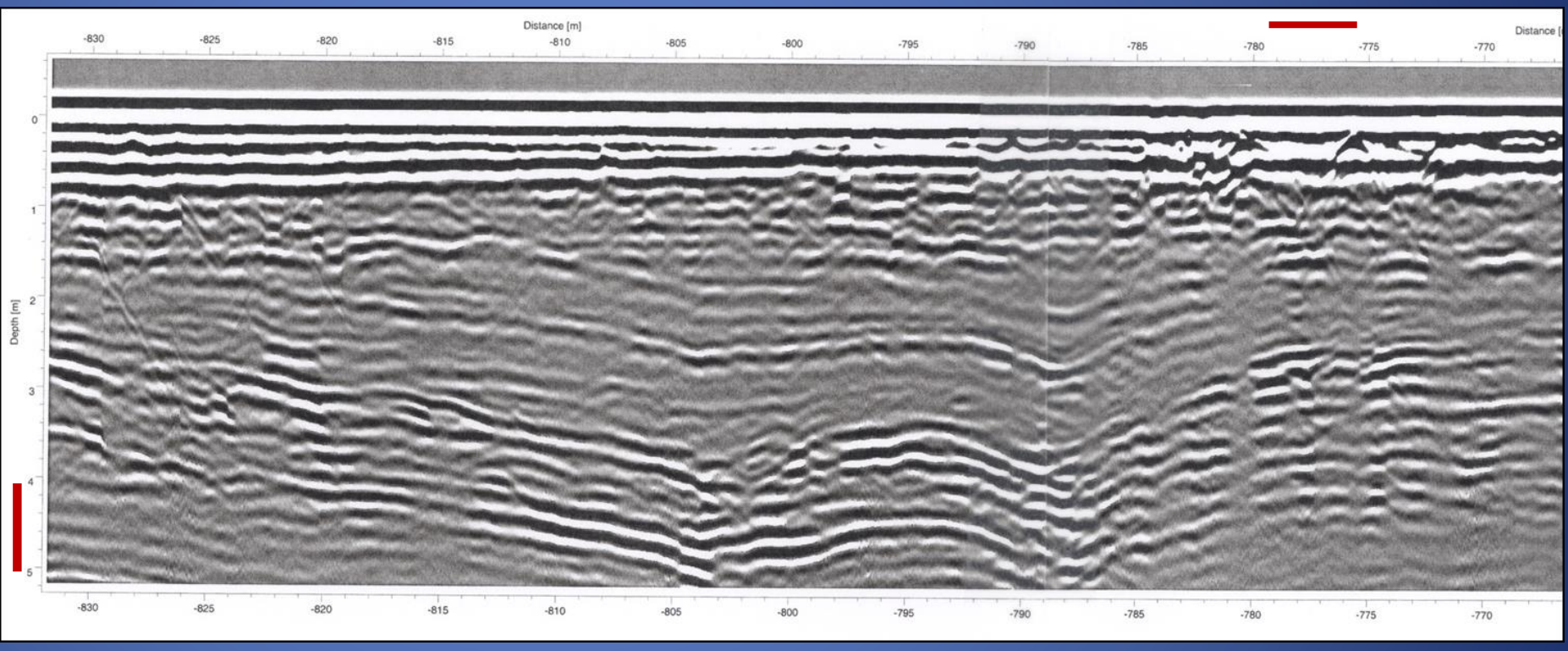

$100 \mathrm{MHz}$ GPR profile 
Sinkhole near Middleground Community, Bulloch County

Diameter 26 meters, Depth to Upper Floridan carbonates $>300 \mathrm{ft}$

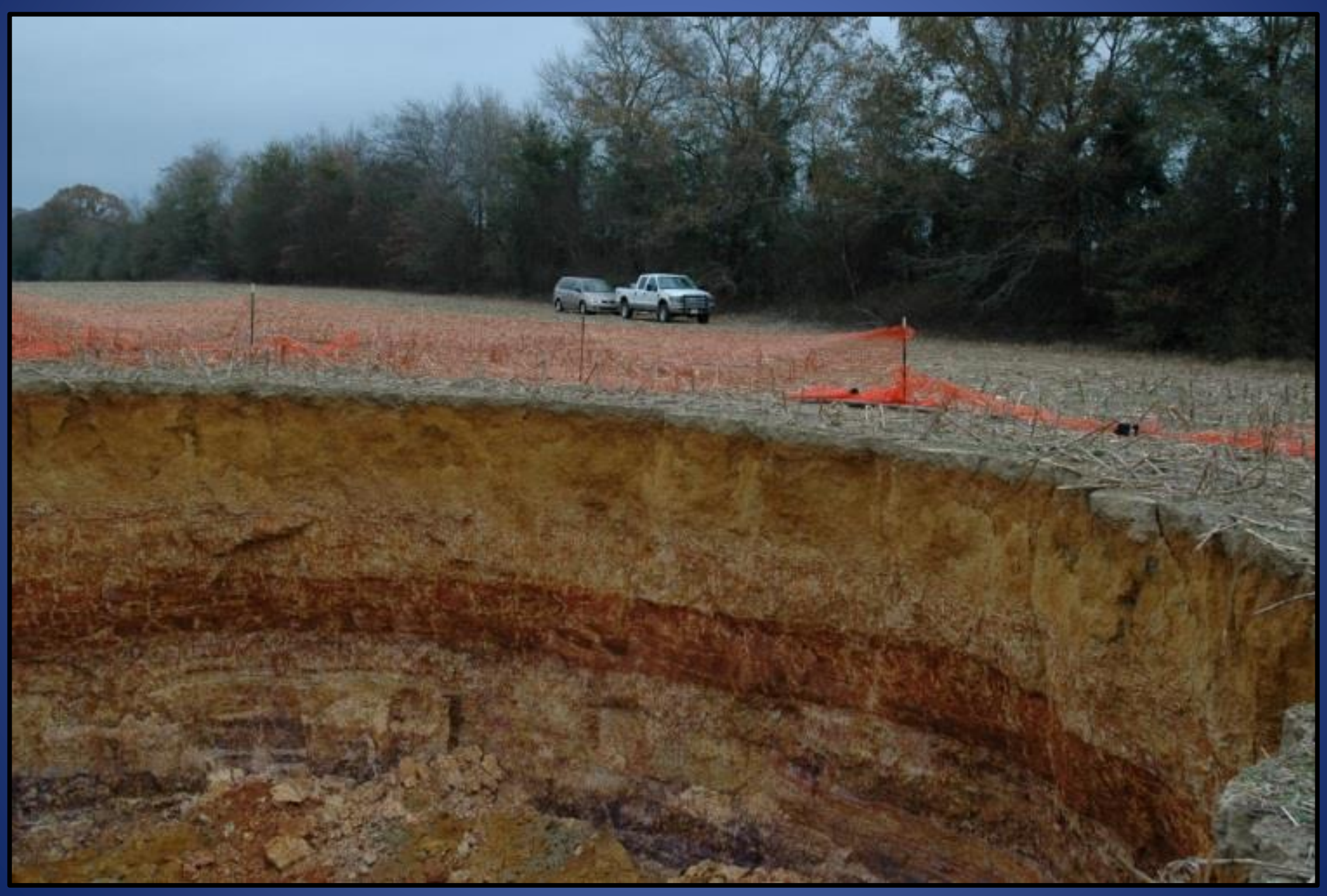




\section{Exploring Links Between Structure and Hydrology}

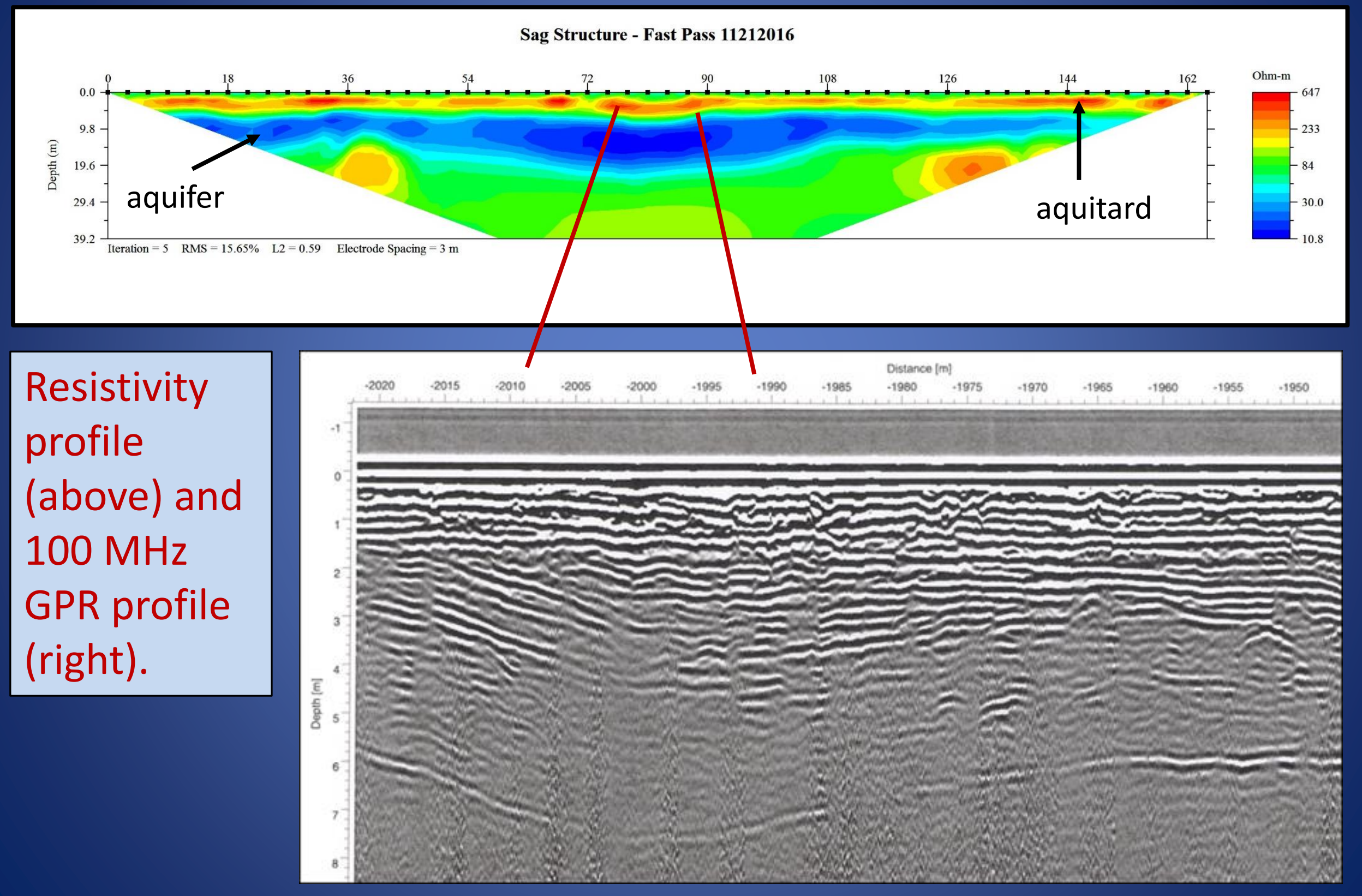


Radar element offsets suggest minor faults and fractures (sag structure with offsets highlighted)

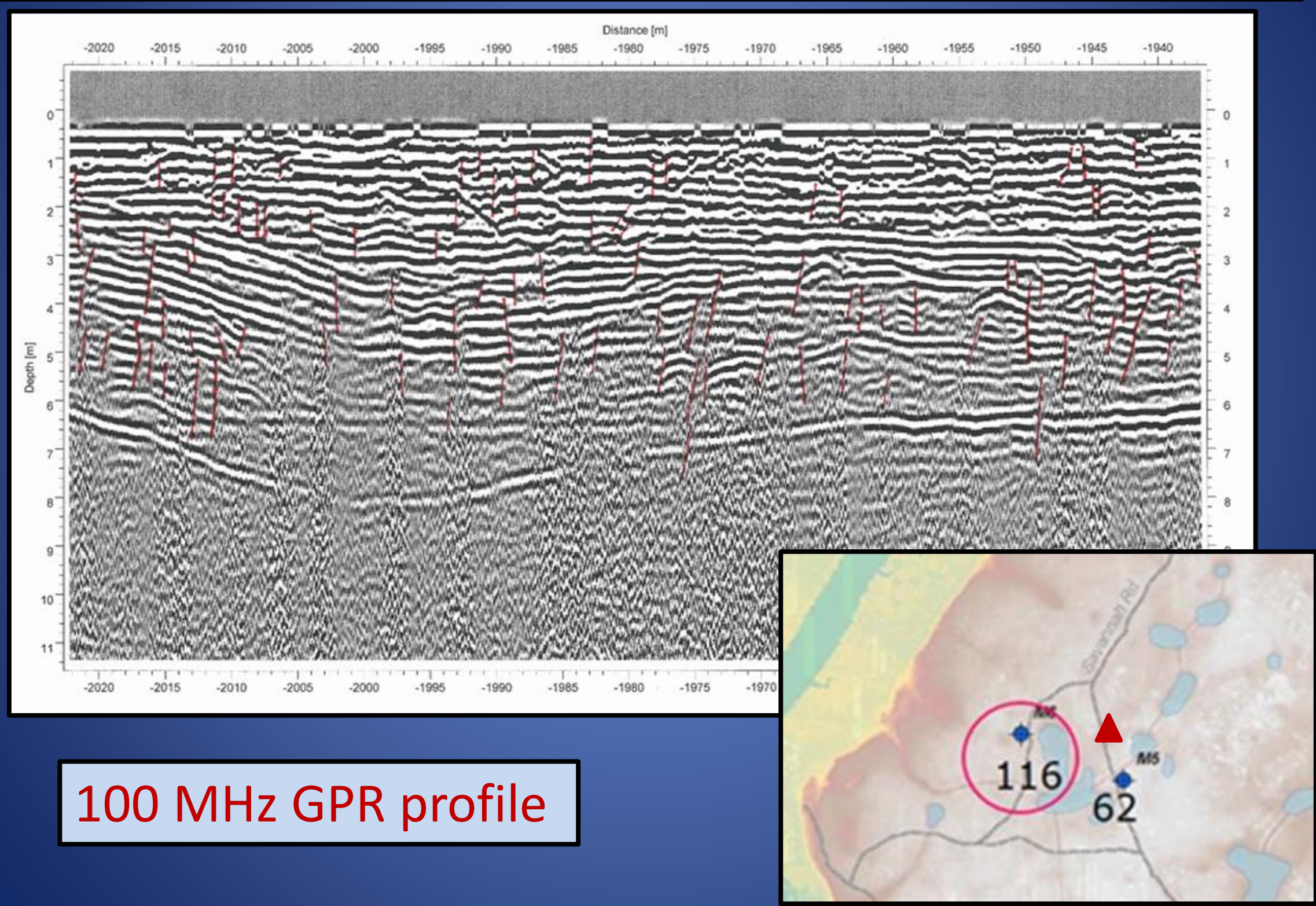



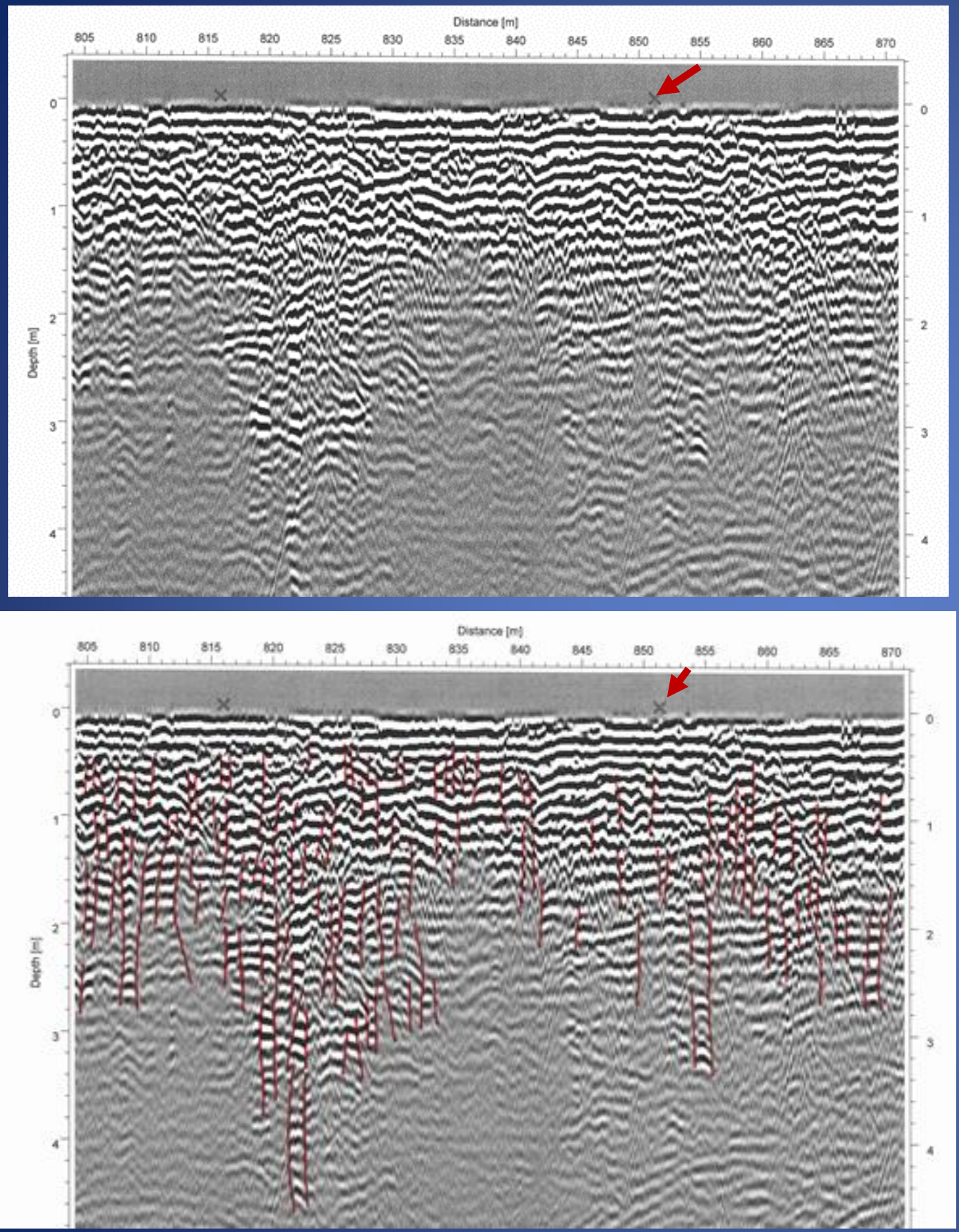

Fault influence at well site $\mathrm{M} 6$ × ?

$250 \mathrm{MHz}$ GPR profile with

highlighted offsets in radar elements

A Test: Are offsets true subsurface displacements or artifacts from surface irregularities? They appear in same location for parallel profiles run from opposite directions. 


\section{$100 \mathrm{MHz}$ GPR}

profile across

NW-SE trending lineaments, offsets highlighted in lower figure
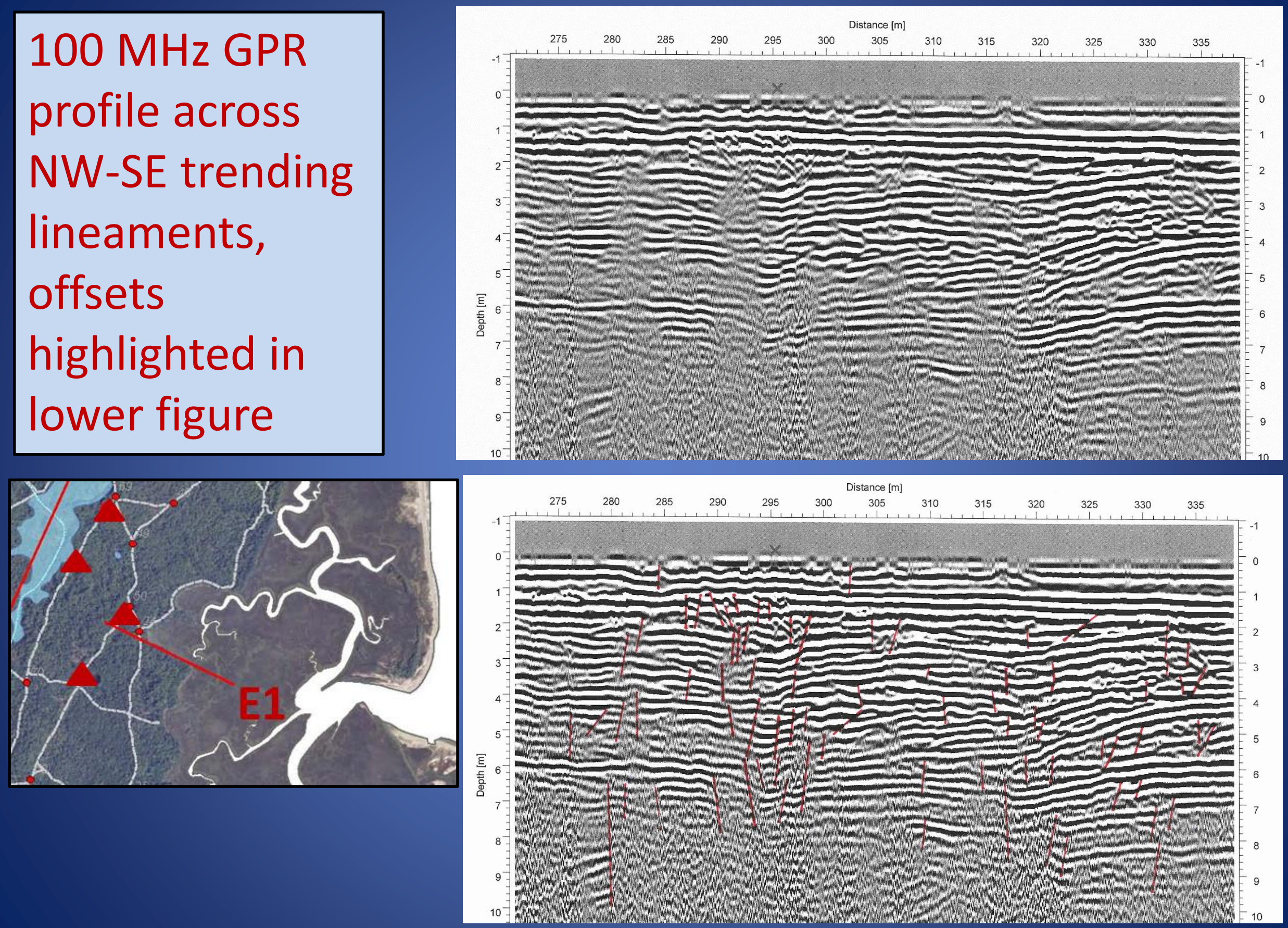


\section{Notes on faulting in soft sediments:}

- Transition from single fault at depth to splays at 35 to 20 m depth (see Basson et al., 2002 combined seismic \& GPR study of Dead Sea Rift.

- Faults may produce deformation bands through combined effects of cataclasis and compaction (See Fossen et al., 2007; Cashman and Cashman, 2000)

- Deformation bands may result in increased density and reduced permeability in band (See Bense, 2004 - Roer Valley Rift study)

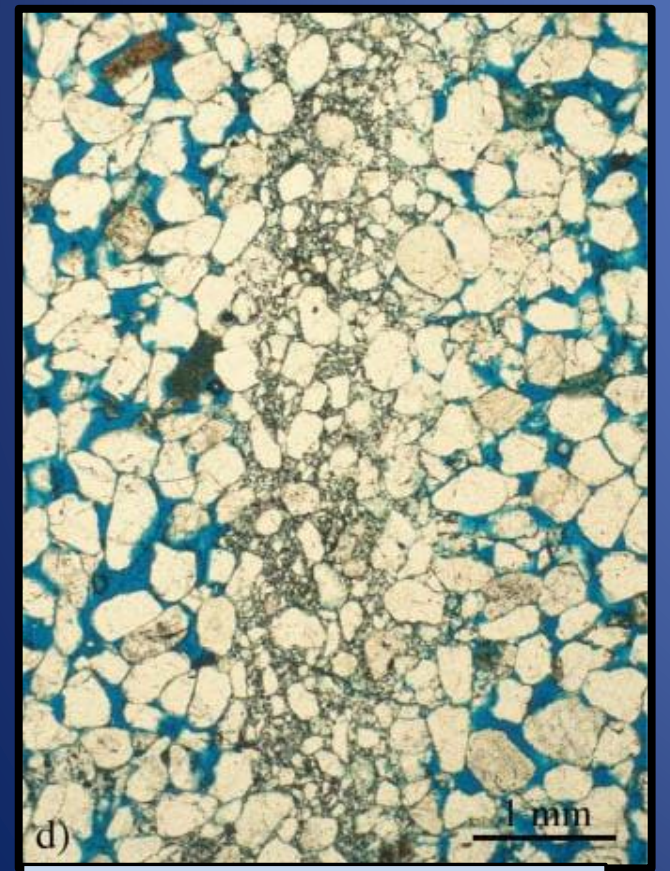

Fossen, et al., 2007

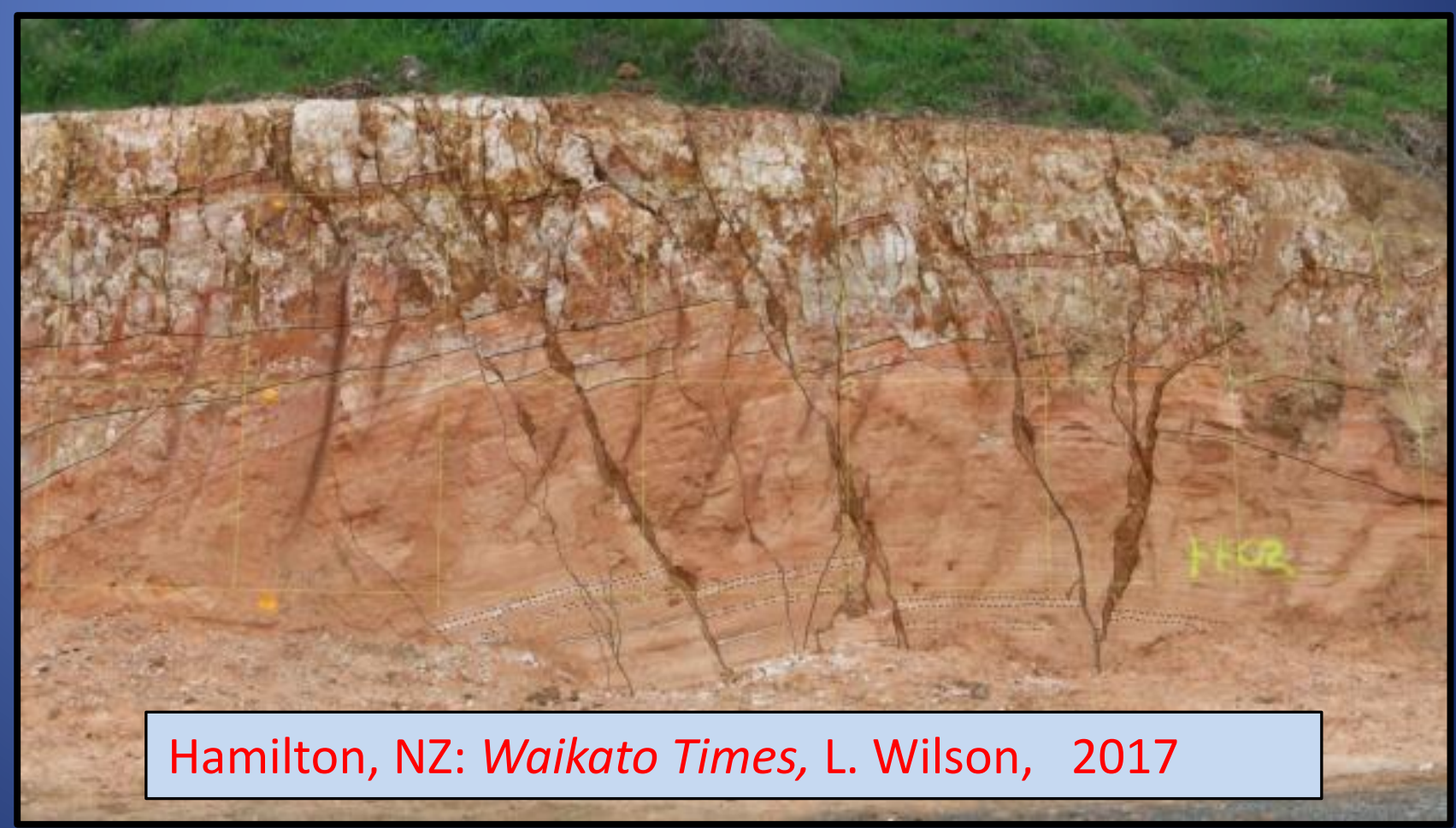




\section{Summary}

- Faults and joints and associated sag structures permitted former Artesian springs and now allow salt water intrusion via upconing.

- The surficial aquifer is also experiencing local salt water intrusion linked to peak tides.

- Structural features (faults and sags) are probably responsible for irregular nature of salt water intrusion in shallow wells.

- Buried channels may be another potential salt water intrusion source. 


\section{Acknowledgements}

Georgia Sea Grant - major research funding

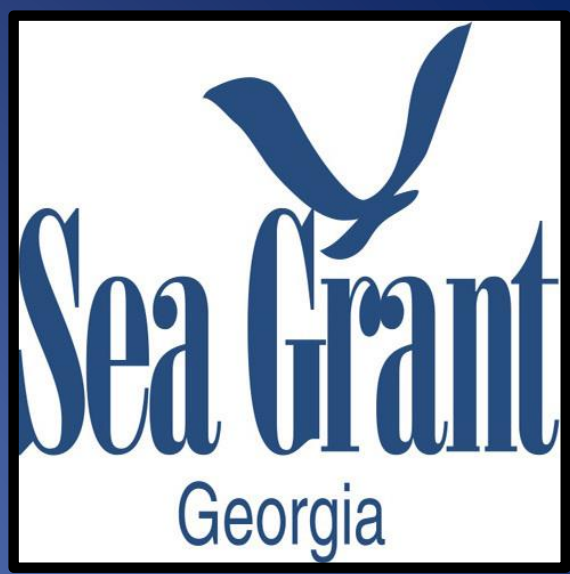

St. Catherines Island Research Foundation - logistical support and housing

Dept. of Geology and Geography - Georgia Southern University Dept. of Geosciences - Georgia State University

Albert Killingsworth - research assistant, Georgia Southern University

GSU \& GSU Student assistants: Erin Brinkman, Scott Thorson, Clara Rucker, Tanner Avery, Douglas Madrid, Jake Swanson, Amber Degon, Jake Lindsay, Lo Anderson, Steven Dobson, Tim Herold, John Bankhead 